\title{
Improvements of Thermal and Thermochemical Properties of Rosin by Chemical Transformation for Its Use as Biofuel
}

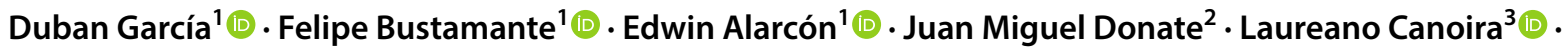 \\ Magín Lapuerta ${ }^{4}$ (i)
}

Received: 23 July 2019 / Accepted: 21 October 2019

(c) Springer Nature B.V. 2019

\begin{abstract}
The use of raw materials from renewable sources has become an important topic for different industries. Pine oleoresin is one of the most important renewable sources. It is composed of a broad range of chemical substances from volatile molecules to complex compounds. The resinic fraction, known as rosin or colophony, comprises approximately $80 \%$ of oleoresin. This fraction has become the most attractive one from the economic standpoint. Rosin is a complex mixture of diterpenic acids and is typically used in formulation of adhesives, coating materials, rubbers, printing inks, among others. Although their transformations have been studied, scarce information on the thermal and thermochemical properties of rosin and rosinderived products has been reported. In this work some of these properties have been estimated to evaluate the influence of chemical transformations such as reduction, isomerization and esterification of rosin components. The estimations have been compared to the literature data and to some experimental values. The interest of some of these transformations is based on the reduction in melting and boiling temperatures observed, although such reductions are probably not enough to use these substances as fuel components.
\end{abstract}

\section{Graphic Abstract}

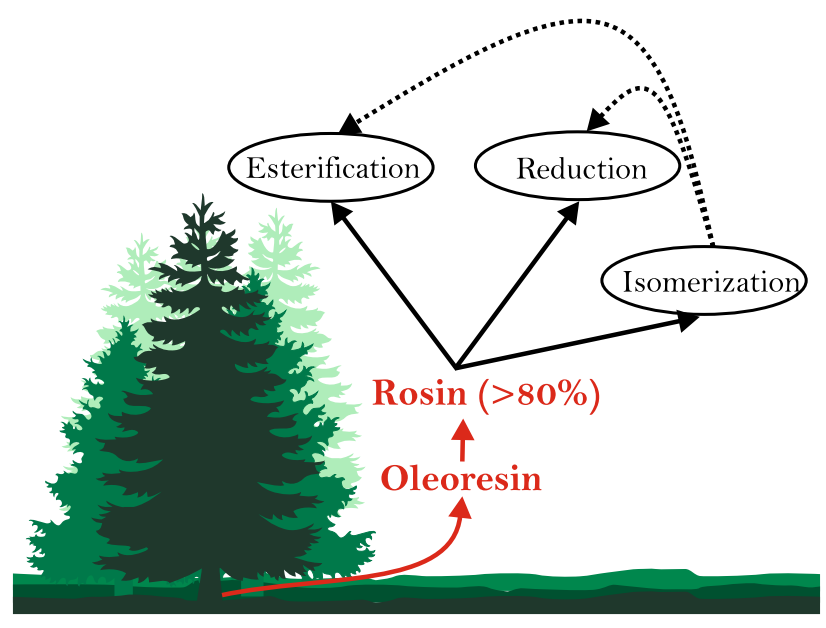

Keywords Rosin $\cdot$ Isomerization $\cdot$ Reduction $\cdot$ Esterification $\cdot$ Properties estimation

Magín Lapuerta

magin.lapuerta@uclm.es

Extended author information available on the last page of the article 


\section{Statement of Novelty}

The use of rosin as fuel could gain high interest in the future from the economic standpoint (rosin is considered a byproduct in paper industry and it is a major component of pine oleoresin). Studies about rosin transformation into fuel components under mild conditions are scarce. This study proposes a simple methodology to identify strengths and weaknesses of the molecules derived from rosin to be used as fuel components, based on widely used estimation tools. No reported study has been found with this kind of analysis for this kind of molecules, and our work provides useful information to take decisions concerning rosin applications, and specifically for use as fuel components.

\section{Introduction}

Rosin or colophony is a mixture of diterpene resin acids grouped in two families: abietic and pimaric acids, according to their molecular structure [1]. Rosin is obtained as the less volatile stream of distillation of oleoresin, which is obtained from conifer trees [1,2]. There are different kinds of rosin depending on the recovery method: wood rosin (extracted from pine stumps), gum rosin (tapped from living pine trees), and tall oil rosin (obtained as a by-product in paper pulp production) [2]. Rosin is employed as chemical intermediary, and in the production of adhesives, tackifiers, chewing gum bases, paper size, printing ink resins, rubber processing aids, coating material and transdermal drug delivery in pharmaceutical, and specialty applications $[1,2]$.

Resin acids display different reactions, such as esterification with polyols (i.e. ethylene glycol, diethylene glycol, glycerol, and pentaerythrol) [2]; decarboxylation to hydrocarbons [3]; oxidation, deoxygenation and isomerization (to abietic, norabietic, palustric, and levopimaric acids) [4]; dehydrogenation or disproportionation (dehydroabietic and di- and tetrahydro- products) [5]; hydrogenation (abietic alcohol, dihydro- and tetrahydro- abietic acid products) and dimerization (dimer abietic acid product is more stable and less toxic than the acid oxide), which make rosin less susceptible to oxidation, and Diels-Alder adducts production with maleic anhydride and fumaric acid [2]; reduction to alcohols and aldehydes, and polymerization [4]. Main transformations of rosin are focused on improving its properties to avoid typical drawbacks of rosin such as auto-oxidation, thermal instability and softening point $[5,6]$. Fuel components (hydrocarbons with molecular weight lower than that for rosin) have been obtained from rosin by catalytic cracking [7, 8], hydrocracking [9], pyrolysis [10] and hydrotreatment [11]. Other transformations attempt to introduce rosin into new markets as, polymers [12,13], herbicides [14], etc., by transforming resin acids into fine and specialty chemicals.

Thermochemical and thermal data for products from rosin are scarce. Analysis of this kind of information is essential to industrial design and scientific research. Particularly, it can help to take decisions on appropriate transformation of chemicals based on desired characteristics of the product [15]. Estimation of properties has evident advantages such as economizing experiments, obtaining information from molecules difficult to separate in pure form, and the possibility to perform analysis of chemical transformations before performing experiments. Different methodologies have been proposed to estimate thermochemical and thermal properties, with group additivity methods being the most popular [16].

Benson method has been widely used to estimate thermochemical properties such as enthalpy and Gibbs energy of formation and heat capacity, of different chemical compounds [16-20]. This methodology is based on hierarchy of additivities, starting from atomic, following by bond and finally the group additivity [21, 22]. Joback and Reid [23] developed a family of group-contribution from a set of molecular groups to estimate thermal properties such as normal boiling and melting temperatures, and critical properties. While Joback method uses structural information until chemical groups (first-order methodology), that proposed by Benson involves information of neighbors (second-order methodology). This second-order group contribution method has been proved to be more precise than the first-order method proposed by Joback [24].

In this work, both first- and second-order methodologies which involve molecular group-contributions were implemented to estimate some thermal and thermochemical properties of rosin and rosin-derived compounds. These compounds can be obtained by transformations such as isomerization, esterification and reduction of resin acids from rosin. By removing the acid functionality, a decrease in thermal properties such as normal melting and boiling temperatures is expected, which is essential for the use of rosin as fuel, but measured values of these properties are scarce in the literature.

Both methods have been widely used, and their results depend on the kind of molecules (molecular structure, weight and complexity), even though, it is well known that these methodologies are not highly accurate, often showing both over- and under-estimations. In order to decrease the inaccuracy of these methods, analysis is performed from changes in properties (delta of melting and boiling temperatures and heat capacity) of pure compounds after and before transformations. Since the purpose of the transformations reviewed in this work is to use rosin-derivates as fuel, low boiling and melting temperatures, and high heating values are desired properties. 


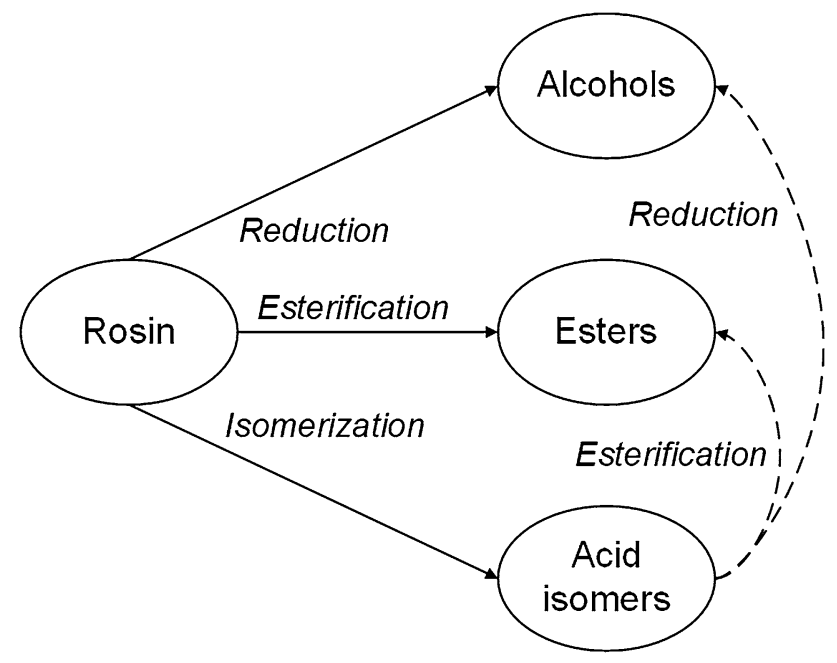

Fig. 1 Transformations of rosin

\section{Materials and Methods}

\section{Experimental}

\section{Materials}

Rosin (technical grade) was supplied by Protokimica S.A. (Medellín, Colombia) and, Resinas Naturales S.A from Cuellar (Segovia, Spain) and Industrias Resineras Valcán (different samples of Spanish rosin). Analytically pure diethyl ether was purchased from Scharlau (Madrid, Spain). Methanol and tetra-methyl-ammonium hydroxide (TMAH) were purchased from Sigma-Aldrich (St, Lois, USA) in analytical grade.

\section{Characterization of Rosin}

Characterization of rosin was performed based on ASTM D5974-15 by GC-MS technique and by using FT-IR. For GC analysis, the samples were dissolved into diethyl ether/ methanol equimolar solution. A subsequent derivatization with TMAH 6\% wt. in methanol was performed by titration using phenolphthalein as indicator. Identification and quantification were carried out in a Agilent 7890 GC system coupled to Agilent 5975C VL MSD triple quadrupole mass detector, equipped with a flame ionization detector (FID) and HP-5 (Agilent J\&W 5\%-Phenyl-methylpolysiloxane) capillary column $(30 \mathrm{~m} \times 0.32-\mathrm{mmi} . \mathrm{d} ., 0.25-\mu \mathrm{m})$. Samples were heated in an oven up to $150{ }^{\circ} \mathrm{C}$ and held for $5 \mathrm{~min}$, then, a $5{ }^{\circ} \mathrm{C} / \mathrm{min}$ heating ramp up to $250{ }^{\circ} \mathrm{C}$ and held for $10 \mathrm{~min}$. Helium was used as carrier gas at linear velocity around $20 \mathrm{~cm} / \mathrm{s}$. Inlet injection and detector temperatures were 300 and $325^{\circ} \mathrm{C}$, respectively. Split ratio of 100:1 was used.

Fourier-transform infrared (FTIR) spectra for rosin was performed in a Perkin Elmer Spectrum 65 with a horizontal attenuated total reflectance (HATR) attachment from 600 to $4000 \mathrm{~cm}^{-1}$.

\section{Measurement of Properties}

Differential scanning calorimetry (DSC) in a TA Q20 was used to measure the boiling and melting temperatures of rosin. Several combinations of variables (flow of nitrogen, weight of sample and speed of heating) were tested, to obtain boiling and melting temperature in DSC equipment. For melting temperature, $10 \mathrm{mg}$ of sample was located in a crucible of aluminium hermetically closed. Nitrogen was used as carrier gas at $50 \mathrm{~mL} / \mathrm{min}$. Once temperature was stabilized at $30{ }^{\circ} \mathrm{C}$, the sample was heated to $200{ }^{\circ} \mathrm{C}$ at $5{ }^{\circ} \mathrm{C} /$ min and kept at this temperature during $10 \mathrm{~min}$, recording the heat released. For boiling temperatures, the weight of
Table 1 Equations to estimate properties with Joback [23]

\begin{tabular}{ll}
\hline Property & Equation \\
\hline Boiling temperature (K) & $T_{b}=198.2+\sum \mathrm{GC}_{J}$ \\
Melting temperature (K) & $T_{m}=122.5+\sum \mathrm{GC}_{J}$ \\
Critical temperature (K) & $T_{c}=T_{b} /\left(0.548+0.965 \sum \mathrm{GC}_{J}-\left(\sum \mathrm{GC}_{J}\right)^{2}\right)$ \\
Critical pressure (bar) & $p_{c}=\left(0.113+0.0032 n_{A}-\sum \mathrm{GC}_{J}\right)^{2}$ \\
Critical volume $\left(\mathrm{cm}^{3} / \mathrm{mol}\right)$ & $v_{c}=17.5+\sum \mathrm{GC}_{J}$ \\
Critical factor of compressibility & $Z_{c}=p_{c} v_{c} / R T_{c}$ \\
Heat of formation $(\mathrm{kJ} / \mathrm{mol})$ & $\Delta h_{f}^{0}=\sum \mathrm{GC}_{J}$ \\
Heat capacity, ideal gas $(\mathrm{J} / \mathrm{mol} \mathrm{K)})$ & $C_{p}^{0}=\sum(a)-37.93+\left(\sum(b)+0.210\right) T+\left(\sum(c)+3.91 \times 10^{-4}\right) T^{2}$ \\
& $+\left(\sum(d)+2.06 \times 10^{-7}\right) T^{3}$
\end{tabular}

$G C_{J}$ group contribution of Joback, $n_{A}$ total number of atoms

$a, b, c$ and $d$ have $\mathrm{GC}_{\mathrm{J}}$ values to be computed as a function of temperature 
<smiles>[R][C@]1(C)CCC[C@]2(C)[C@H]3CC[C@@](C)(C=C)C=C3CC[C@H]12</smiles>

Pimaric<smiles>[R][C@]1(C)CCC[C@@]2(C)[C@H]1CCC1=CC(C(C)C)=CC[C@@H]12</smiles>

Levopimaric<smiles>[R][C@]1(C)CCC[C@]2(C)c3ccc(C(C)C)cc3CC[C@@H]12</smiles>

Dehydroabietic<smiles>[R][C@]1(C)CCC[C@]2(C)[C@H]3CC=C4C[C@](C)(C=C)CC[C@H]4[C@H]3[C@H]12</smiles>

Isopimaric<smiles>[R][C@]1(C)CCC[C@]2(C)C3=C(C=C(C(C)C)CC3)CC[C@@H]12</smiles>

Palustric<smiles>[Z][C@]1(C)CCC[C@]2(C)[C@H]3CCC(=C(C)C)C=C3CC[C@H]12</smiles>

Neoabietic<smiles>[R][C@]1(C)CCC[C@]2(C)[C@H]3C=C[C@H]4C[C@](C)(C=C)CC[C@H]4[C@]3(C)[C@H]12</smiles>

Sandaracopimaric<smiles>[R][C@]1(C)CCC[C@@]2(C)[C@H]1CC=C1C=C(C(C)C)CC[C@@H]12</smiles>

Abietic<smiles>[R][CH]CCO</smiles>

Fig. 2 Molecular structure for rosin acids and derivates

samples was $5 \mathrm{mg}$, and were heated to $400{ }^{\circ} \mathrm{C}$, with a flow of nitrogen of $20 \mathrm{~mL} / \mathrm{min}$, while the other conditions were kept similar to the tests for melting temperature.

\section{Estimations}

Analysis of influence of chemical transformation on thermal and thermochemical properties of rosin was performed 


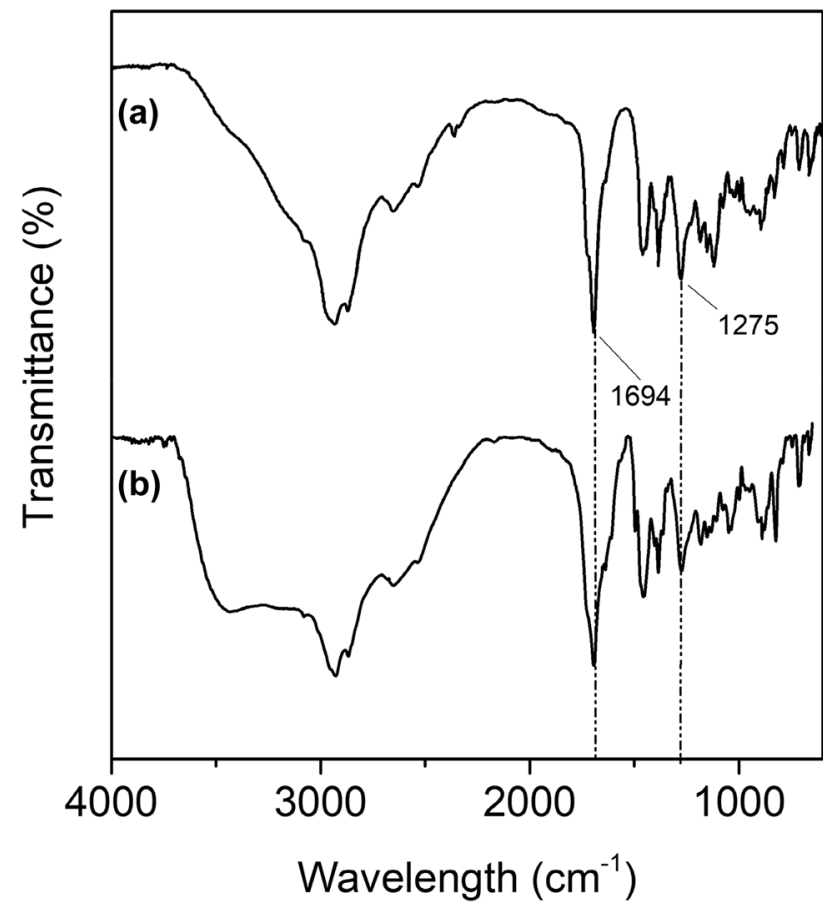

Fig. 3 FT-IR spectra for $\mathbf{a}$ Spanish and $\mathbf{b}$ Colombian rosin
Critical compressibility factor, volume, pressure and temperature, and heat capacity were computed by using Joback methodology. Estimation equations are summarized in Table 1.

Heat of formation $(\mathrm{kJ} / \mathrm{mol})$ from Benson methodology was obtained by Eq. 9,

$\Delta h_{f}^{0}=\sum \mathrm{GC}_{B}$

where $\mathrm{GC}_{B}$ represents the group contribution of Benson methodology.

Lower heating value ( $\mathrm{LHV}, \mathrm{MJ} / \mathrm{kg}$ ) for species were derived from Benson's estimation of heat of formation, Eq. 10,

$L H V=\frac{\Delta h_{f, \text { comb. Prod. }}^{0}-\Delta h_{f, \text { species }}^{0}}{M W}-\Delta h_{\mathrm{v}}^{0}$

where $M W$ is the molecular weight of each species, $\Delta h_{f \text {,species }}^{0}$ and $\Delta h_{f \text {,comb. Prod. }}^{0}$ represent the heat of formation of each species and major combustion products (usually $\mathrm{CO}_{2}$ and water), respectively, and $\Delta h_{\mathrm{v}}^{0}$ is the heat of vaporization. From the principle of corresponding states and by using the Pitzer correlation, heat of vaporization $(\mathrm{kJ} / \mathrm{mol})$ was determined according to Eq. 11,

according to Fig. 1. The chemical reactions evaluated were reduction, esterification, and isomerization of rosin compounds. Isomerization was also analyzed as previous step of reduction and/or esterification.

$\Delta h_{\mathrm{v}}^{0}=R T_{c}\left(7.08\left(1-298.15 / T_{c}\right)^{0.354}+10.95\left(1-298.15 / T_{c}\right)^{0.456} \omega\right)$

Table 2 Composition of rosin

\begin{tabular}{|c|c|c|c|c|c|c|}
\hline \multirow[t]{3}{*}{ Compound $^{\mathrm{a}}$ (acids) } & \multicolumn{6}{|c|}{ Concentration (\% wt.) } \\
\hline & \multicolumn{2}{|c|}{ Measured } & \multicolumn{4}{|c|}{ Typical values [26] } \\
\hline & Spain & Colombia & USA & China & Honduras & India \\
\hline Pimaric & 8.7 & 2.3 & 5.1 & 9.2 & 9.6 & 9.2 \\
\hline Sandaracopimaric & 1.5 & 0 & 1.8 & 2.7 & 2.2 & 1.5 \\
\hline Communic & 0 & 0 & 2.8 & 0 & 0 & 0 \\
\hline Isopimaric & 0 & 11.2 & 17 & 1.5 & 17 & 20 \\
\hline Levopimaric/Palustric & 27 & 29.7 & 25 & 22 & 21 & 11 \\
\hline Dehydroabietic & 1.9 & 19.7 & 5.7 & 4.3 & 12 & 2 \\
\hline Abietic & 36 & 21.1 & 22 & 44 & 22 & 38 \\
\hline Neoabietic & 24 & 10.9 & 20 & 15 & 15 & 18 \\
\hline Others & 0.9 & 5.1 & 0.6 & 1.3 & 1.2 & 0.3 \\
\hline
\end{tabular}

${ }^{\text {a }}$ Molecular formula for all acids is $\mathrm{C}_{20} \mathrm{H}_{30} \mathrm{O}_{2}$ except dehydroabietic acid $\left(\mathrm{C}_{20} \mathrm{H}_{28} \mathrm{O}_{2}\right)$ 

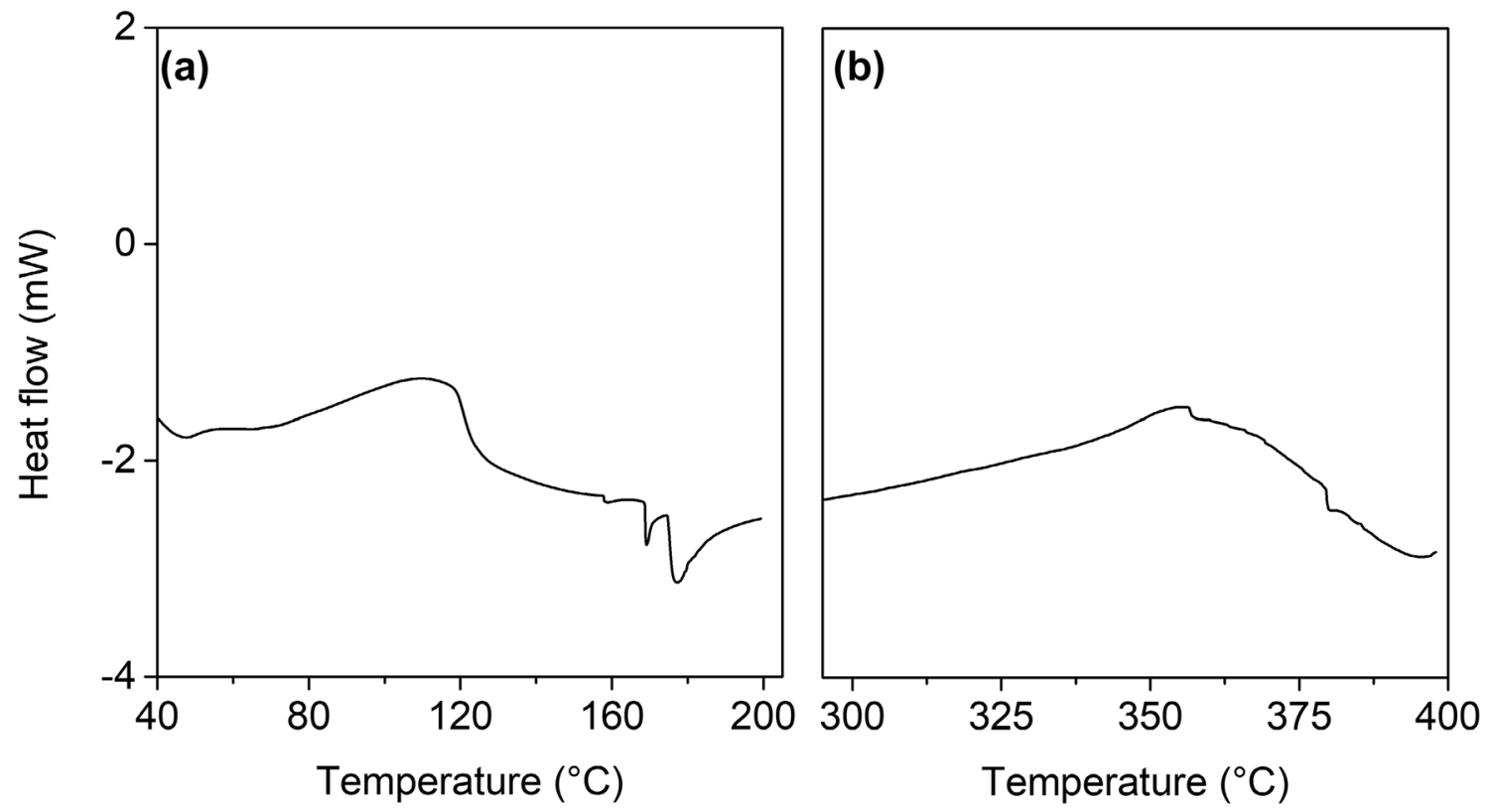

Fig. 4 Thermogram for Spanish rosin: $\mathbf{a}$ melting temperature and $\mathbf{b}$ boiling temperature regions

where $\omega$ is the acentric factor obtained by implementing the Lee-Kesler method of vapor pressure and by using critical values and boiling temperature from Joback, according to Eq. 12,
Molecular structure of rosin compounds and their derivates are shown in Fig. 2.

Functionalities of molecules are represented by A in Fig. 2. Direct reduction of acids from rosin leads the

$$
\begin{aligned}
& \ln \left(1 / p_{c}\right)=f^{(0)}+\omega \cdot f^{(1)} \\
& f^{(0)}=5.92714-\frac{6.09648 \cdot T_{c}}{T_{b}}-1.28862 \cdot \ln \left(T_{b} / T_{c}\right)+0.169347\left(T_{b} / T_{c}\right)^{6} \\
& f^{(1)}=15.2518-\frac{15.6875 \cdot T_{c}}{T_{b}}-13.4721 \cdot \ln \left(T_{b} / T_{c}\right)+0.43577\left(T_{b} / T_{c}\right)^{6}
\end{aligned}
$$

Table 3 Boiling and melting temperatures of rosin components and rosin-derived molecules

\begin{tabular}{lllll}
\hline & Compound & Acid & Methyl ester & Alcohol \\
\hline$T_{b}{ }^{a}\left({ }^{\circ} \mathrm{C}\right)$ & Dehydroabietic & ND & ND & $177[27]$ \\
& Abietic & $315-385[28]$ & $362.5[29]$ & $164[30]$ \\
$T_{m}{ }^{b}\left({ }^{\circ} \mathrm{C}\right)$ & Pimaric & $218-219[31]$ & ND & $85-86[32]$ \\
& Sandaracopimaric & $218[33]$ & $67-68[34]$ & ND \\
& Isopimaric & $175[35]$ & ND & $86-87[36]$ \\
& Levopimaric & $150-152[37]$ & $63-64[38]$ & ND \\
& Palustric & $163-164[39]$ & ND & ND \\
& Dehydroabietic & $171-171.5[39]$ & $62.3-63.9[40]$ & ND \\
& Abietic & $172-174[41,42]$ & $25-84[29,38]$ & $79-81[43]$ \\
& Neoabietic & $165-167[44]$ & $61.5-62[45]$ & $96-97[46]$ \\
\hline
\end{tabular}

$N D$ no experimental data

${ }^{a}$ Boiling temperature

${ }^{\mathrm{b}}$ Melting temperature 
formation of alcohols ( $\mathrm{r}$ in Fig. 1), while the reaction between carboxylic acids and an alcohol produces methyl esters (e in Fig. 1). Isomerization (i in Fig. 1) is analyzed as a previous homogenization step for diverse acids from rosin before undergoing reduction and/or methyl esterification.

\section{Results and Discussion}

\section{Experimental Measurements}

\section{Characterization of Rosin}

FTIR spectra for samples of rosin produced in Spain and that commercially available in Colombia are shown in Fig. 3.

FTIR spectrum for both samples of rosin in Fig. 3 display a sharp peak at $1694 \mathrm{~cm}^{-1}$ attributed to stretching of $\mathrm{C}=\mathrm{O}$ acid. The peak at $1275 \mathrm{~cm}^{-1}$ can be assigned to the stretching vibration $\mathrm{C}-\mathrm{O}$ bond of the carboxylic group [25]. Consequently, the main group evidenced in both samples of rosin is carboxylic acid, as expected. FTIR spectra for Colombian rosin depicts the presence of surface water with a broad band in the region $3200-3500 \mathrm{~cm}^{-1}$.

Measured composition of Spanish rosin and that commercially available in Colombia is compared to typical composition of rosin from different countries [26], as shown in Table 2.

According to Table 2, abietic acid is the main compound of rosin, followed by neoabietic, isopimaric and levopimaric/

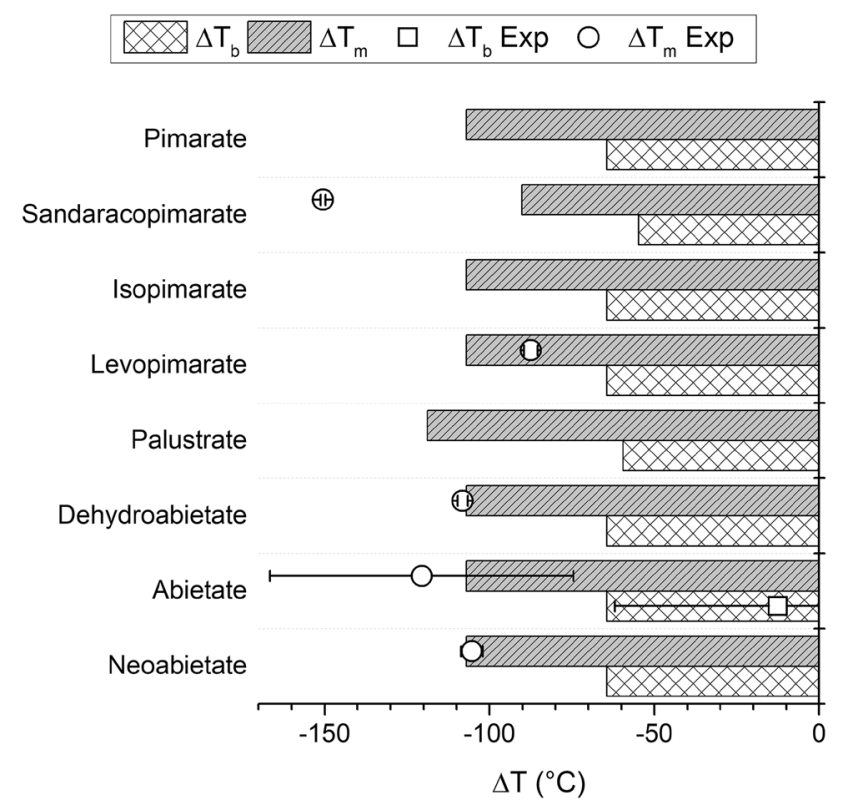

Fig. 5 Deltas of melting and boiling temperature due to methyl esterification of rosin palustric acids. Communic acid is present only in American rosin and in a very low concentration, and therefore it is ignored in the analysis. Besides, levopimaric and palustric acid concentrations are usually reported together due to the difficulty to separate them by gas chromatography.

The interest of the proposed transformations of rosin compounds derives from possible improvements in properties of resin acids. In particular, decreases in viscosity and melting and boiling temperatures are expected by performing reduction and methyl esterification of resin acids, which are solid at normal conditions. Previous isomerization can help to homogenize the spectrum of properties of acids in rosin.

\section{Measured Properties}

Thermogram obtained for Spanish rosin is shown in Fig. 4. In the region of melting temperature (Fig. 4a) two prominent peaks can be observed, which can be attributed to the change of phase of the sample. According to the composition in Table 2, the main component of rosin is abietic acid, followed by neoabietic acid, and based on the intensities of the peaks, the melting temperature for abietic and neoabietic acids are 178.07 and $169.17^{\circ} \mathrm{C}$, respectively.

The presence of different resin acids in rosin makes the change from liquid to vapor phase smooth (see Fig. 4b), with only two minor peaks being notice at 357 and $380{ }^{\circ} \mathrm{C}$, which can be assigned to neoabietic and abietic acid, respectively, based on the intensities.

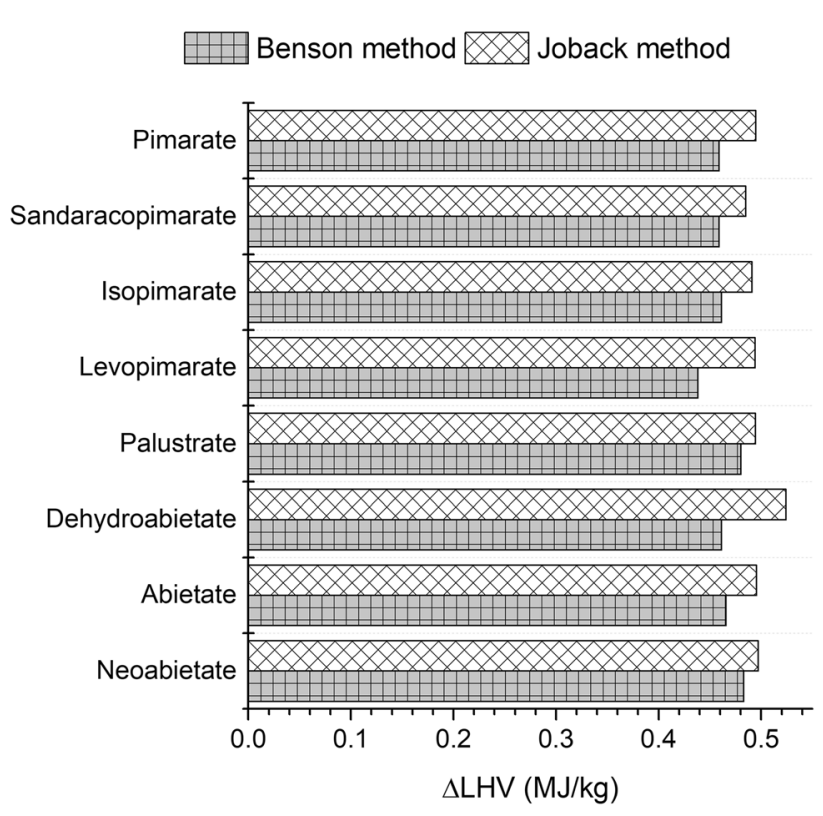

Fig. 6 Deltas of lower heating value due to methyl esterification of rosin 


\section{Data from Literature}

A detailed literature revision of experimental data, especially for boiling and melting temperatures, for pure components of rosin and products of esterification and reduction reactions was performed. Experimental values of boiling and melting temperatures for molecules reported in literature are shown in Table 3. Only abietic acid and its derivates (methyl abietate and abietyl alcohol) have experimental boiling and melting temperatures experimentally reported in the literature as shown in Table 3, although a wide range of values is observed. In general, reported boiling temperatures of resin acids from rosin and rosin-derived molecules are scarce. Experimental values of melting temperatures have been reported more often than boiling ones for rosin compounds and its derivates. Melting temperatures obtained in present work for abietic and neoabietic acids are slightly higher than that reported in literature $\left(2-4{ }^{\circ} \mathrm{C}\right)$.

Boiling temperature obtained in present work for abietic acid is in the range of reported values. Melting temperature for abietic and neoabietic acid measured in present work are slightly higher than that reported in the literature; around 4 and $2{ }^{\circ} \mathrm{C}$ for abietic and neoabietic acids, respectively, above the upper limit of reported values.

\section{Estimations}

Analysis of estimated properties of rosin and its derived compounds is carried out in terms of changes of properties

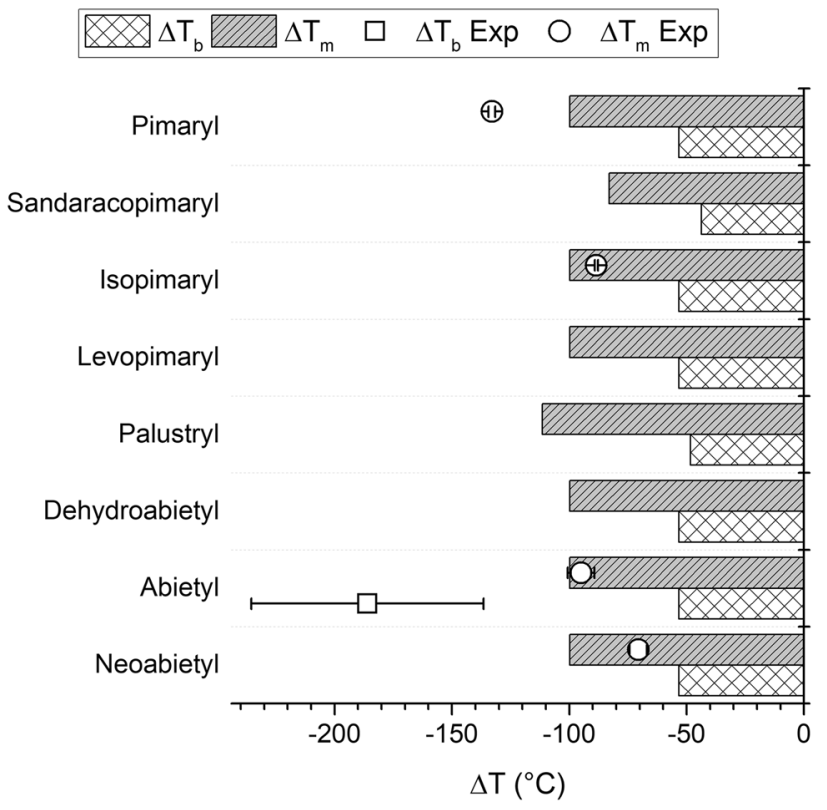

Fig. 7 Delta of melting and boiling temperature due to reduction of rosin (deltas) due to chemical transformations (methyl esterification, reduction and isomerization).

\section{Methyl Esterification of Rosin}

The influence of esterification reaction on melting and boiling temperature is shown in Fig. 5. Average values from experimental ones in Table 3 are presented, including the experimental values measured in present work, and error bars represent the standard deviation.

Joback method predicts the same delta of boiling temperatures under esterification reaction for pimaric, isopimaric, levopimaric, dehydroabietic, abietic and neoabietic acids $\left(\Delta T_{B}=-64.8^{\circ} \mathrm{C}\right)$, while for sandaracopimaric and palustric acids deltas were -54.8 and $-59.5^{\circ} \mathrm{C}$, respectively. Decrease in boiling temperature of abietic acid from experimental data (Table 3) after methyl esterification is $-12.5^{\circ} \mathrm{C}$ in average, which is lower than that estimated with Joback method (only the upper limit of the experimental delta is close to Joback estimation). Although Joback method typically overestimates boiling and melting temperatures, the experimental boiling temperature of abietic acid has a wide range of values, and experimental value of boiling temperature of methyl abietate is in the middle of this range. Chemically, a reduction in boiling temperature is expected after esterification. Whence, some experimental data of boiling temperature for abietic acid might be erroneous.

Estimated deltas of melting temperatures with Joback method under esterification reaction are very close to the experimental ones for neoabietic and dehydroabietc acids,

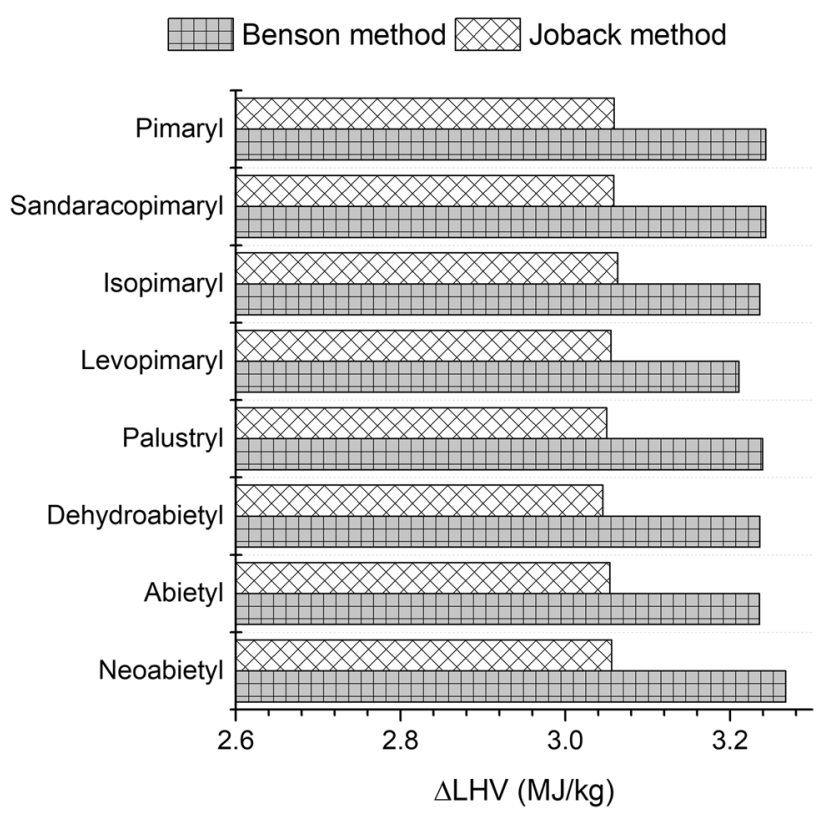

Fig. 8 Delta of lower heating values due to reduction of rosin 
while the group contribution method underestimates delta of melting temperature for sandaracopimaric and abietic acids (although for abietic acid it is within the experimental deviation) and overestimates that for levopimaric acid, according to experimental data from Table 3.

Pimaric skeleton is shared by pimaric, isopimaric and sandaracopimaric acids. The only difference between them is the position of an instauration inside the rings. Nevertheless, experimental delta of melting temperature from Table 3 is substantially higher for sandaracopimaric acid than for the others, without apparent reason. In general, good agreement was obtained with Joback method for changes in melting temperatures under esterification reaction of rosin compounds.

Deltas of lower heating value estimated for esterification of rosin compounds by using Benson and Joback methods are shown in Fig. 6. In general, Joback method estimates higher values than Benson method, probably due to Joback neglecting the contribution of neighboring groups. In any case, esterification of rosin components into corresponding methyl esters has a minor effect on heating values, because an increment about barely $0.5 \mathrm{MJ} / \mathrm{kg}$ is observed in estimations.

Under the assumption that all components of rosin are completely converted under a esterification reaction, the product of esterification of Spanish rosin (for instance) according to Table 2 , has a reduction of melting temperature of $108.3{ }^{\circ} \mathrm{C}$, a reduction in boiling temperature of $63.6{ }^{\circ} \mathrm{C}$ and an increase in heating values about $0.5 \mathrm{MJ} / \mathrm{kg}$, which means appreciable changes in properties of methyl rosinate with respect to rosin. Despite the acid group being removed from their molecular structures, a high tendency to remain as solid of methyl rosinate is still maintained with a minor increase in heating values.

If methyl rosinate components are compared with typical methyl esters from vegetable oils (i.e. biodiesel), melting temperatures of former are in any case higher than those of methyl stearate and palmitate $\left(38.9\right.$ and $33.5^{\circ} \mathrm{C}$ [47], respectively). Considering that biodiesel has often experienced filter clogging problems derived from both impurities (mainly mono-, di- and triglycerides and glycerol) and for saturated esters, the reduction in melting point of methyl rosinate compounds seems to be insufficient.

\section{Reduction of Rosin}

Delta of melting and boiling temperatures due to reduction reaction of rosin are shown in Fig. 7. Delta of boiling temperature for alcohols derived from rosin compounds are slightly lower than those for the corresponding methyl esters, as shown in Fig. 7. As in the case of esterification of rosin, the unique experimental delta of boiling temperature is appreciably higher than its estimation. Besides, measured delta of boiling temperature for abietyl alcohol shows high dispersion due to the high dispersion of experimental boiling temperatures for abietic acid.

Experimental and estimated delta of melting temperatures from reduction of abietic and isopimaric acids are very similar. Difference in melting temperature due to reduction reaction for neoabietic and pimaric acids are over- and underestimated by Joback method, respectively, but estimations and experimental data are in the same order of magnitude. As in the case of esterification reaction, alcohols from abietic and levopimaric acids have the lowest melting temperatures $\left(15^{\circ} \mathrm{C}\right.$ lower than those of other alcohols derived from rosin compounds).

Estimations of delta for lower heating value, for reduction of rosin compounds, with Joback and Benson methods are shown in Fig. 8. Unlike the estimated deltas in lower heating values due to esterification of rosin, values obtained with Benson method for reduction of rosin compounds are higher than Joback ones. This is because the contribution of hydroxyl groups from Benson is higher than that from Joback, while that for carboxyl groups is lower. In all cases (lower heating values from Joback and Benson methods) the difference between compounds are minor (see Fig. 8). The reduction reaction of rosin compounds shows a stronger effect on the lower heating value than esterification. Lower heating values are increased in more than $3 \mathrm{MJ} / \mathrm{kg}$, which is a significant change.

By performing a reduction reaction to Spanish rosin, for instance, melting temperature has a reduction of $101.1^{\circ} \mathrm{C}$, boiling temperature is reduced $52.5^{\circ} \mathrm{C}$ and lower heating value is increased about $3 \mathrm{MJ}$. Melting and boiling temperatures of alcohols from rosin are 7.2 and $11.1^{\circ} \mathrm{C}$ more than methyl rosinate, respectively, indicating higher propensity of reduced compounds from rosin to remain as solid in comparison to methyl esters, but compounds obtained by reduction of rosin gave higher heating values than rosin and methyl rosinate ones.

\section{Isomerization of Rosin}

Appreciable differences in melting and boiling temperatures of rosin compounds can be observed (see Table 3). Pimaric and sandaracopimaric acids have the highest melting temperatures, which makes them the most propense rosin compounds to remain solid. Their presence in the mixture implies that unmodified rosin is unsuitable for fuel applications. Otherwise, levopimaric acid has the lowest melting temperature. In fact, the difference in melting temperature between levopimaric and pimaric acid reaches around $65^{\circ} \mathrm{C}$, which is a large difference for such similar molecules. In this case, isomerization reaction of rosin compounds can be an interesting transformation, as far as acids with high melting 
temperature are removed and the average melting temperature of resulting acids becomes lower.

Unfortunately, experimental information for some rosinderivates (methyl esters and alcohols shown in Table 3) is missing. Hence, estimated properties can be helpful to select a target compound for isomerization previous to reduction and/or esterification reactions. Molecules derived from levopimaric and abietic acids, through both reduction and esterification reactions, showed the lowest melting and boiling temperatures, suggesting that these molecules can be good candidates to be a target molecule in an isomerization reaction. Besides, lower heating values are similar among all rosin-derivates resulting from either reduction or esterification reactions (i.e. around $36.4 \mathrm{MJ} / \mathrm{kg}$ after methyl esterification and around $38.9 \mathrm{MJ} / \mathrm{kg}$ after reduction, in both cases using Benson method).

\section{Conclusions}

Experimental values of boiling and melting temperatures for abietic and neoabietic acid (the main components of Spanish and Colombian rosins), and the lower heating value for rosin, were obtained. Measured melting temperatures were slightly higher than the upper limit of literature data, while boiling point for abietic acid is inside the range of reported data.

Large discrepancy between estimated and measured boiling temperatures for rosin and rosin-derived compounds was observed. However, scarcity of experimental information makes estimation necessary. However, it should be remarked that the accuracy of group contribution methods such as that proposed by Joback for the estimation of thermal properties is low. Enough experimental data was only found for abietic acid and their derived molecules (abietyl alcohol and methyl abietate), and large differences were observed in the experimental values.

According to estimations of expected products of rosin transformations proposed in this work (and supported on some experimental data), significant decrease in melting and boiling temperatures can be expected. Esterification of rosin compounds leads the formation of esters with melting temperatures around $108{ }^{\circ} \mathrm{C}$ lower than resin acids, while the heating values remain almost constant. Reduction reaction leads to the formation of alcohols with melting temperatures slightly lower than those for esters but with higher heating values. Molecules derived from levopimaric and abietic acids showed best thermal properties among rosin compounds, with similar lower heating values, which makes them good candidates for an isomerization reaction.

Although reduction reaction increases significantly the lower heating value of rosin compounds, and methyl esterification reaction decreases appreciably the boiling and melting temperatures, both benefits are considered insufficient, mainly because the expected products will still have high propensity to remain as solid. Consequently, it is likely that these transformations are unsuitable for fuel applications.

Acknowledgements Colciencias is gratefully acknowledged for the scholarship (call 272 of 2015) supporting D.G and project 37-1-693 (ref. FP44842-124-2017). Universidad de Antioquia is acknowledged for the research project PRG2014-1091.

\section{References}

1. Yadav, B.K., Gidwani, B., Vyas, A.: Rosin: recent advances and potential applications in novel drug delivery system. J. Bioact. Compat. Polym. 31, 111-126 (2016). https://doi. org/10.1177/0883911515601867

2. Höfer, R.: Chapter $3 \mathrm{~B}$ - the pine biorefinery platform chemicals value chain. In: Pandey, A., Höfer, R., Taherzadeh, M., Nampoothiri, K.M., Larroche, C. (eds.) Industrial Biorefineries \& White Biotechnology. Elsevier, Amsterdam (2015)

3. Wideman, L.G., Kuczkowski, J.A.: Decarboxylation of rosin acids, EU Patent No. 0149958A2, (1985)

4. Silvestre AJD (2008) Chapter 4-rosin: major sources, properties and applications. In: Monomers, Polymers and Composites from Renewable Resources. Elsevier, Amsterdam

5. Souto, J.C., Yustos, P., Ladero, M., Garcia-Ochoa, F.: Disproportionation of rosin on an industrial $\mathrm{Pd} / \mathrm{C}$ catalyst: Reaction pathway and kinetic model discrimination. Bioresour. Technol. 102, 3504-3511 (2011). https://doi.org/10.1016/j.biortech.2010.11.022

6. Wang, L., Chen, X., Liang, J., Chen, Y., Pu, X., Tong, Z.: Kinetics of the catalytic isomerization and disproportionation of rosin over carbon-supported palladium. Chem. Eng. J. 152, 242-250 (2009). https://doi.org/10.1016/j.cej.2009.04.052

7. Clark, I.T., Harris, E.E.: Catalytic cracking of rosin 2. J. Am. Chem. Soc. 74, 1030-1032 (1952). https://doi.org/10.1021/ja011 $24 \mathrm{a} 046$

8. Bernas, A., Salmi, T., Murzin, D.Y., Mikkola, J.-P., Rintola, M.: Catalytic transformation of abietic acid to hydrocarbons. Top. Catal. 55, 673-679 (2012). https://doi.org/10.1007/s1124 4-012-9846-7

9. Mikulec, J., Kleinová, A., Cvengroš, J., Joríková, L., Banič, M.: Catalytic transformation of tall oil into biocomponent of diesel fuel. Int. J. Chem. Eng. 2012, 1-9 (2012). https://doi. org/10.1155/2012/215258

10. Lappi, H.E., Alén, R.J.: Pyrolysis of cruded tall oil-derived products. BioResources 6, 5121-5138 (2011)

11. Coll, R., Udas, S., Jacoby, W.A.: Production of diesel fuel additives from the rosin acid fraction of crude tall oil. Prog. Thermochem. Biomass. Convers. (2001). https://doi.org/10.1002/9780470694954.ch127

12. Wilbon, P.A., Chu, F., Tang, C.: Progress in renewable polymers from natural terpenes, terpenoids and rosin. Macromol. Rapid Commun. 34, 8-37 (2013). https://doi.org/10.1002/marc.201200513

13. Ojagh, H., Creaser, D., Salam, M.A., Grennfelt, E.L., Olsson, L.: Hydroconversion of abietic acid into value-added fuel components over sulfided NiMo catalysts with varying support acidity. Fuel Process. Technol. 190, 55-66 (2019). https://doi.org/10.1016/j. fuproc.2019.03.008

14. Gao, Y., Li, L., Chen, H., Li, J., Song, Z., Shang, S., Song, J., Wang, Z., Xiao, G.: High value-added application of rosin as a potential renewable source for the synthesis of acrylopimaric acidbased botanical herbicides. Ind. Crops Prod. 78, 131-140 (2015). https://doi.org/10.1016/j.indcrop.2015.10.032

15. Kazakov, A., Muzny, C.D., Chirico, R.D., Diky, V.V., Frenkel, M.: Web Thermo Tables-an on-line version of the TRC 
thermodynamic tables. J. Res. Natl. Inst. Stand. Technol. 113, 209 (2012). https://doi.org/10.6028/jres.113.016

16. Bhattacharya, A., Shivalkar, S.: Re-tooling Benson's group additivity method for estimation of the enthalpy of formation of free radicals: C/H and C/H/O Groups. J. Chem. Eng. Data. 51, 11691181 (2006). https://doi.org/10.1021/je0503960

17. Janbazi, H., Hasemann, O., Schulz, C., Kempf, A., Wlokas, I., Peukert, S.: Response surface and group additivity methodology for estimation of thermodynamic properties of organosilanes. Int. J. Chem. Kinet. 50, 681-690 (2018). https://doi.org/10.1002/kin.21192

18. Domalski, E.S., Hearing, E.D.: Estimation of the thermodynamic properties of hydrocarbons at 298.15 K. J. Phys. Chem. Ref. Data. 17, 1637-1678 (1988). https://doi.org/10.1063/1.555814

19. Roganov, G.N., Pisarev, P.N., Emel'yanenko, V.N., Verevkin, S.P.: Measurement and prediction of thermochemical properties. Improved Benson-type increments for the estimation of enthalpies of vaporization and standard enthalpies of formation of aliphatic alcohols. J. Chem. Eng. Data. 50, 1114-1124 (2005). https://doi. org/10.1021/je049561m

20. Morales, G., Martinez, R.: Thermochemical properties and contribution groups for ketene dimers and related structures from theoretical calculations. J. Phys. Chem. A. 113, 8683-8703 (2009). https://doi.org/10.1021/jp9030915

21. Cohen, N.: Revised group additivity values for enthalpies of formation (at $298 \mathrm{~K}$ ) of carbon-hydrogen and carbon-hydrogenoxygen compounds. J. Phys. Chem. Ref. Data. 25, 1411-1481 (1996). https://doi.org/10.1063/1.555988

22. Benson, S.W., Golden, D.M., Haugen, G.R., Shaw, R., Cruickshank, F.R., Rodgers, A.S., O'neal, H.E., Walsh, R.: Additivity rules for the estimation of thermochemical properties. Chem. Rev. 69, 279-324 (1969). https://doi.org/10.1021/cr60259a002

23. Joback, K.G., Reid, R.C.: Estimation of pure-component properties from group-contributions. Chem. Eng. Commun. 57, 233-243 (1987). https://doi.org/10.1080/00986448708960487

24. Lapuerta, M., Rodríguez-Fernández, J., Oliva, F.: Determination of enthalpy of formation of methyl and ethyl esters of fatty acids. Chem. Phys. Lipids. 163, 172-181 (2010). https://doi. org/10.1016/j.chemphyslip.2009.11.002

25. Wang, L., Ding, S., Gan, P., Chen, X., Zhang, D., Wei, X., Wang, $\mathrm{X}$.: A supported nano $\mathrm{ZnO}$ catalyst based on a spent fluid cracking catalyst (FC3R) for the heterogeneous esterification of rosin. React. Kinet. Mech. Catal. 119, 219-233 (2016). https://doi. org/10.1007/s11144-016-1022-9

26. Zinkel, D.F., Rusell, J.: Naval stores: Production, chemistry, utilization. Pulp Chemicals Association, New York, New York, NY (1989)

27. Fieser, L.F., Campbell, W.P.: Hydroxyl and amino derivatives of dehydroabietic acid and dehydroabietinol. J. Am. Chem. Soc. 61, 2528-2534 (1939). https://doi.org/10.1021/ja01878a080

28. Tschirch, A., Wolff, M.: The occurrence of abietic acid in resin oil. Arch. der Pharm. 245, 1-4 (1908)

29. Syracuse Research Corporation of Syracuse, N.Y. (US): SciFinder data.

30. Kono, M., Maruyama, R.: Chemistry of coccids produced in Japan. XI. The resinous constituents of Ceroplastes rubens Mask. I. Nippon Nogei Kagaku Kaishi. 12, 512-520 (1936)

31. Kutan, I.: Separation of pimaric acid from resin of ordinary pine Pinus silvestris. Zhurnal Prikl. Khimii 36, 1149-1151 (1963)
32. Shmidt, E.N., Pentegova, V.A.: High-boiling neutral compounds from the oleoresin of Pinus silvestris. Izv. Sib. Otd. Akad. Nauk SSSR, Seriya Khimicheskikh Nauk. 144-146 (1968)

33. Rollett, A., Tabakoff, P., Feimer, S.: Acid constituents of sandarac resin. Monatsh. Chem. 50, 1-5 (1928)

34. De Pascual Teresa, J., San Feliciano, A., Miguel del, C.M.J.: Components of Juniperus oxycedrus fruits. An. Quim. 70, 1015-1019 (1974)

35. Chang, L.C., Song, L.L., Park, E.J., Luyengi, L., Lee, K.J., Farnsworth, N.R., Pezzuto, J.M., Kinghorn, A.D.: Bioactive constituents of Thuja occidentalis. J. Nat. Prod. 63, 1235-1238 (2000). https://doi.org/10.1021/np0001575

36. Grant, P.K., Huntrakul, C., Sheppard, D.R.J.: Diterpenes of Dacrydium bidwillii. Aust. J. Chem. 20, 969-972 (1967). https:// doi.org/10.1071/CH9670969

37. Lazarev, M.Y., Zaretskii, M. V: X-ray structural analysis of levopimaric acid. Sin. Org. Soedin. 127-137 (1970)

38. Lombard, R., Ebelin, J.: The hydrogenation of the resin acids of pine gums. II. Bull. Soc. Chim. Fr. 930-936 (1953)

39. Bardyshev, I.I., Cherches, K.A.: Dehydroabietic and palustric acids as component parts of the rosin of Picea excelsa. Dokl. Akad. Nauk SSSR. 116, 959-960 (1957)

40. Gu, W., Wang, S.: Synthesis and antimicrobial activities of novel 1H-dibenzo[a, c]carbazoles from dehydroabietic acid. Eur. J. Med. Chem. 45, 4692-4696 (2010). https://doi.org/10.1016/J.EJMEC H.2010.07.038

41. Komshilov, N.F.: High-melting abietic acid. Zhurnal Prikl Khimii 30, 1111-1115 (1957)

42. Nong, W., Chen, X., Wang, L., Liang, J., Wang, H., Long, L., Huang, Y., Tong, Z.: Measurement and correlation of solid-liquid equilibrium for abietic acid+alcohol systems at atmospheric pressure. Fluid Phase Equilib. 367, 74-78 (2014). https://doi. org/10.1016/j.fluid.2014.01.018

43. Yadav, J.S., Baishya, G., Dash, U.: Synthesis of (+)-amberketal and its analog from 1-abietic acid. Tetrahedron 63, 9896-9902 (2007). https://doi.org/10.1016/j.tet.2007.06.063

44. Tsutsui, M.: Japanese pine resins. XI. The isolation of resin acid by the brucine salt technique: the isolation of retene-type acids. Nippon Kagaku Kaishi. Pure Chem. 496-498 (1953)

45. Harris, G.C., Sanderson, T.F.: Resin acids. I. An improved method of isolation of resin acids; isolation of a new abietic-type acid, neoabietic acid. J. Am. Chem. Soc. 70, 334-339 (1948). https:// doi.org/10.1021/ja01181a104

46. Pigulevskii, G.V., Kostenko, V.G.: Neoabietic and abietic acidsprimary resin acids from oleoresin of the Siberian fir Abies sibirica. Zhurnal Prikl Khimii 33, 439-444 (1960)

47. Murray, S.M., O’Brien, R.A., Mattson, K.M., Ceccarelli, C., Sykora, R.E., West, K.N., Davis, J.H.: The fluid-mosaic model, homeoviscous adaptation, and ionic liquids: dramatic lowering of the melting point by side-chain unsaturation. Angew. Chem. 49, 2755-2758 (2010). https://doi.org/10.1002/anie.200906169

Publisher's Note Springer Nature remains neutral with regard to jurisdictional claims in published maps and institutional affiliations. 


\section{Affiliations}

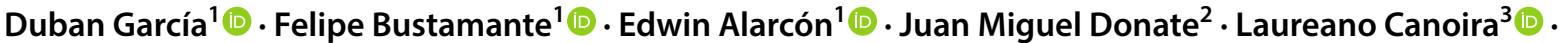 Magín Lapuerta ${ }^{4}$}

1 Environmental Catalysis Research Group, Engineering Faculty, Chemical Engineering Department, Universidad de Antioquia UdeA, Calle 70 No. 52-21, Medellín, Colombia

2 Industria Resinera Valcán, S.A., Ctra. de Alcázar, s/n., 16003 Cuenca, Spain
3 Department of Energy and Fuels, ETS de Ingenieros de Minas y Energía, Universidad Politécnica de Madrid, Rios Rosas, 21, 28003 Madrid, Spain

4 Escuela Técnica Superior de Ingenieros Industriales, University of Castilla - La Mancha, Edificio Politécnico, Avda. Camilo José Cela, s/n., 13071 Ciudad Real, Spain 